\title{
Sorption of Radionuclides to Building Materials and its Removal Using Simple Wash Solutions
}

\author{
Michael Kaminski, ${ }^{*}$ Carol Mertz, Luis Ortega, Nadia Kivenas \\ Nuclear Engineering Division, Argonne National Laboratory \\ *Corresponding author: Telephone: 630-252-4777 \\ Fax: 630-972-4499 \\ Kaminski@anl.gov
}

\begin{abstract}
Decontamination after a nuclear or radiological release requires a detailed understanding of the materials hosting the contamination, the chemistry of the radionuclide, and the chemical properties of the decontamination agent. Urban contamination via a number of radiological release scenarios may require simple decontamination methods that can be deployed for wide-area decontamination. This paper investigates a number of factors of importance for developing such decontamination methods, focusing on cesium. These factors include the influence on decontamination approaches from the cesium deposition conditions, the urban building material composition and, when washing with an ionic solution that is utilized for decontamination, the composition of the wash solutions. In summary, the sorption chemistry of cesium onto urban building materials and roadways has been studied to develop simple decontamination methods that can be deployed for wide-area decontamination efforts.

To improve the understanding of the sorption of cesium onto common urban building materials and roadways the desorption of cesium deposited from solution and as a dry powder was tested. Using ammonium $\left(\mathrm{NH}_{4}{ }^{+}\right)$salt solutions, we tested the desorption of ionic cesium bound to individual components of concrete and coupons of several common building materials. While the tests on concrete aggregate suggest that a concentration $>10 \mathrm{mM} \mathrm{NH}_{4}{ }^{+}$does not improve the desorption of cesium, tests on concrete, asphalt, marble, limestone and granite monoliths showed improved decontamination factors when the $\mathrm{NH}_{4}{ }^{+}$concentration increased from 0.1 to $0.5 \mathrm{M}$. We also found that cesium as dry particulate material could be removed quite effectively although the contamination became tenacious upon wetting the surface.
\end{abstract}

\section{KEYWORDS}

Decontamination; remediation; radioactive contamination; ammonium; cesium-137, concrete.

\subsection{INTRODUCTION}

An airborne release of radioactive material may occur primarily from three sources -- a nuclear weapon detonation, a nuclear reactor core accident, or a radionuclide dispersal device (RDD). Each source can contaminate large areas of urban and rural land. Depending on the mechanism for release of the radioactive material and the environmental conditions, the method for remediating affected areas contaminated with the radioactive fallout material may differ drastically. For example, actinide elements tend to condense quickly, forming large agglomerated 

radionuclides such as cesium-134 and cesium-137 are much more volatile than the actinides, highly soluble in water, can form compounds/complexes with many other substances, are known to condense onto the fine dust in the fallout from an explosive discharge [1] or a reactor core accident [2], and can travel long distances in the plume [3]. The prevalence of highly soluble salt forms of concentrated cesium-137 used in industry and government suggests that potential RDD sources may produce similarly condensed soluble forms of cesium.

Radiological decontamination is a well-established field in the nuclear industry, practiced during routine operations [4] or in decommissioning of a nuclear facility [5]. However, remediating an urban or rural environment for unrestricted use is not common practice because of the cost and scale of the remediation effort. The Chernobyl nuclear reactor accident in 1986 proved that we are not prepared to remediate an urban or rural environment for unrestricted use even though Nordic researchers had begun to investigate wide-area decontamination $[6,7]$. The Exclusion Zone surrounding the Chernobyl reactor persists and, most recently, the reactor accidents at Fukushima showed we are still ill-prepared for such large scale remediation efforts.

Because of the density of inhabitants and of economic activity the remediation of the urban environment and, particularly, the hard external surfaces of buildings and roadways is an area of pressing concern. The recommended practice for decontaminating these surfaces relies primarily on methods for small-particle removal (vacuuming, sweeping, washing/rinsing with water). Ideally, the decontamination technique should treat large areas quickly. For cesium sorbed to loose particulate or debris, the first step is to remove this loose material. However, rain or even humidity can render cesium into solution as cations that can bond to copious negative sorption sites present on building materials such as clays, rock minerals, and cement. Once bound to the surface, the surface needs to be physically removed or chemically treated to promote the desorption of cesium cations. Moreover, any cesium that had become irreversibly bound into the network of transition metal oxides or carbonates would be essentially unavailable for removal except by methods that chemically or physically scoured the surfaces. In a wide-area remediation effort conducted outdoors, such techniques using aggressive chemicals to etch the surface or scabbling tools might be too laborious or time consuming to complete. Instead, simpler methods are sought. For example, a fire hose can distribute water to wash down building roofs, facades, and paved areas rapidly. However, washing cesium with water from a fire hose is generally ineffective, as studies have demonstrated $[7,8]$. There were simply insufficient ions present to desorb the solubilized cesium that was bound strongly to ion exchange sites on the building materials.

To improve decontamination of cesium, researchers tested solutions containing cations similar to cesium in ion exchange properties since ion exchange is believed to be an important mechanism in the immobilization of solubilized cesium onto common building materials, especially immediately after deposition. Sandalls [9] first reported the use of an ammonium nitrate wash to remove cesium from building materials, employing the ion exchange properties of ammonium nitrate that are very similar to cesium (cationic charge density and resultant hydrated radii). Ahn et al. [10] employed ammonium-loaded clay suspensions to decontaminate cesium deposited on brick and slate but found that the ammonium provided only marginal improvement in decontamination factors compared to the clay suspension alone. DeWitt et al. [11] found that ammonium concentrations above $0.2 \mathrm{M}$ generally improved decontamination factors only marginally for concrete, asphalt and clay tiles. Real et al. [12] reported dramatic improvement in the removal of cesium deposited on clay tile and concrete as an aerosol using aqueous ammonium 
solutions. Drake and MacKinney [13] recently discussed several approaches for decontamination technologies and tools for use after radionuclides, including cesium, are released from a radiological dispersal device. Demmer et al. summarized methods used to date at Chernobyl and Goiania [14], including the advent of benchmark testing methods [15]. Most recently, the EPA has reported results from testing ionic formulations on concrete, granite, marble, limestone and asphalt [16], and Kaminski et al. [17] reported the development of a system for washing buildings and roadways with potassium or ammonium salt solution, containing the produced waters, and treating remaining cesium on-site, thereby enabling reuse of water during decontamination operations.

To improve the understanding of the sorption of cesium onto common urban building materials and roadways, the desorption of cesium deposited from solution and as a dry powder was tested. Using aqueous $\mathrm{NH}_{4}{ }^{+}$salt solutions, we tested the desorption of ionic cesium bound to individual components of concrete and coupons of several common building materials. While the tests on concrete aggregate suggest that a concentration $>10 \mathrm{mM} \mathrm{NH}_{4}{ }^{+}$does not improve desorption of cesium, tests on concrete, asphalt, marble, limestone and granite monoliths showed improved decontamination factors when the $\mathrm{NH}_{4}{ }^{+}$concentration increased from 0.1 to $0.5 \mathrm{M}$. Cesium as dry particulate material could be removed quite effectively, although the contamination became tenacious upon wetting the surface.

\subsection{METHODS}

All chemicals used were reagent grade or better, and all solutions used deionized water $\left(\sim 18 \mathrm{M} \Omega \cdot \mathrm{cm}\right.$ resistivity at $\left.25^{\circ} \mathrm{C}\right)$. The ammonium chloride solutions were prepared by adding the salt to tap water. The cesium-137 stock solution was obtained from in-house stores and was analyzed by inductively coupled plasma-mass spectrometry (ICP-MS) for potential contaminants after acidifying with Optima nitric acid (ELAN DRC II, PerkinElmer/SCIEX, calibrated with standards prepared from NIST-traceable solutions procured from Ultra Scientific, North Kingstown RI. Reported data were calculated from the ICP-MS concentration data and the dilution factors of the samples. Samples were acidified to $1 \% \mathrm{HNO} 3$ prior to analysis.). The results verified the purity of the stock solution (Table 1).

Cesium-137 in solution and sorbed to aggregate or coupon surfaces was monitored by gamma-ray spectroscopy with either an NaI detector (Minaxi $\gamma$ Auto-Gamma 5000 Series Gamma Counter, United Technologies Packard, Model A5550, using 12 x 75 polypropylene tubes, Perkin-Elmer) or a high purity germanium detector (ORTEC GEM-35190-P, 35\% efficiency, calibrated with Co-60, Cs-137, Eu-152, and Am-241 sources) for the $662 \mathrm{keV}$ photopeak $18 \mathrm{~cm}$ from the detector face for 5-10 min live time. The percent removal of cesium was computed from the initial counts on the coupon or aggregate $C_{i}$ from the final counts measured on the coupon or aggregate $C_{f}$ by:

$$
\% \text { Cs-137 removal }=\frac{C_{i}-C_{f}}{C_{f}} \times 100
$$

TABLE 1. ICP-MS and gamma* analysis results of Cs-137 stock solution

\begin{tabular}{lcc}
\hline Element & $\begin{array}{c}\text { Concentration } \\
(\boldsymbol{\mu g} / \mathbf{L})\end{array}$ & $\begin{array}{c}\text { Estimated } \\
\text { Accuracy }\end{array}$ \\
\hline Lithium & $<7.2$ & $\pm 13 \%$ \\
Boron & $<25.5$ & $\pm 18 \%$
\end{tabular}




\subsection{Concrete aggregate batch tests}

A commercially-available concrete mix (Quikrete ${ }^{\circ}$, standard 4000 psi concrete mix purchased from a local home supply store) was separated by sieving into the following components: cement powder $(<0.15 \mathrm{~mm}, 15 \%$ by mass $)$, fine aggregate $(0.15-2 \mathrm{~mm}, 45 \%$ by mass), and coarse aggregate ( $>2 \mathrm{~mm}, 40 \%$ by mass). The fine and coarse aggregate fractions were rinsed with deionized water and dried before testing. Cement pieces were prepared by mixing Portland cement (Quikrete $®)$ with deionized water at a ratio of 2.5:1 cement-to-water. The cement paste was poured into $31.75 \mathrm{~mm}$ diameter, $6.35 \mathrm{~mm}$ thick molds to prepare cement monoliths that were cured in a hydrated environment for at least 30 days prior to use. The monoliths were cracked into small pieces of $\sim 2 \mathrm{~mm}$ and used for testing.

To contaminate the samples, approximately $5.0 \mathrm{~g}$ of concrete material (one of the following: cement pieces, fine aggregate or coarse aggregate) was weighed into a polystyrene test tube. An aliquot of $4.75 \mathrm{~mL}$ of deionized water was added to the sample. The sample was spiked with $0.25 \mathrm{~mL}$ of the Cs-137 stock solution and gently mixed for 60 minutes in a rotating mixer. Then, the sample was centrifuged, and the supernatant was removed for $\gamma$-counting before adding $5 \mathrm{~mL}$ of deionized water to rinse the entrained liquid. The rinse was immediately removed for $\gamma$-counting.

Decontamination of the sample was performed by adding $5 \mathrm{~mL}$ of a wash solution to the test tube and gently rotating for 60 minutes. After decontamination, the samples were centrifuged, and the wash solution was removed for $\gamma$-counting. Insignificant activity was found in the rinse except for the tests with cement. A rinse of $5 \mathrm{~mL}$ of deionized water was added to the sample and removed immediately for $\gamma$-counting. The decontaminated samples were analyzed with the HPGe detector. Triplicate samples were run for all tests in this section unless specified otherwise.

\subsection{Static soak tests}

We wished to assess the maximum removal of cesium from the surface by soaking the coupon face in solution. First, concrete monolithic coupons were prepared by adding $83 \mathrm{~mL}$ of deionized water per $\mathrm{kg}$ of concrete mix. The concrete was mixed for three minutes and allowed to rest for several minutes. The concrete was mixed again for another three minutes before it was pressed into $3.8 \mathrm{~cm}$ tall $\times 3.18 \mathrm{~cm}$ diameter $(1.5$ " tall $\times 1.25$ " diameter) pieces of plastic pipe. The top surface was smoothed with a spatula to form a smooth cement surface. The monoliths were 
covered with plastic wrap and kept moist by misting occasionally with water. The monoliths were removed from the mold after 10 to 15 days and kept in a moist environment. The monoliths were ready for use after 40 days of curing. Then, a thin layer of epoxy (5-Minute Epoxy 14270, Devcon, Danvers, MA) was applied to the sides of the monoliths to prevent sorption of cesium during testing (lack of sorption of cesium onto the epoxy was verified by separate tests not shown).

Coupons were contaminated by using a pipette tip to spread $100 \mu \mathrm{L}$ of a dilute Cs-137 stock solution ( 20,000 counts $/ \mathrm{min} / 100 \mu \mathrm{L}$ at $18 \mathrm{~cm}$ from the detector) evenly on the coupon surface. This contamination level was chosen to facilitate detection using our gamma detectors and because it represents a low level of contamination $\left(<0.04 \mu \mathrm{Ci} / \mathrm{cm}^{2}\right.$ or $<3 \times 10^{5} \mathrm{cpm}$ per coupon) not unlike what has been reported from areas surrounding Fukushima-Daiichi [18] (up to 10's of thousands cpm per detector scan area within Fukushima Prefecture). The coupons sat until they were visibly dry, wrapped in plastic, and $\gamma$-counted.

After contamination and overnight aging (70-80\% relative humidity, 20-25 $\left.{ }^{\circ} \mathrm{C}\right)$, concrete coupons were suspended on a Teflon ${ }^{\circledR}$ grid for 1 hour in $6 \mathrm{~mL}$ of solution (deionized water, tap water, and ammonium chloride salt solutions) in a Petri dish. At selected time intervals, $200 \mu \mathrm{L}$ aliquots were withdrawn for gamma analysis. After $1 \mathrm{~h}$, the concrete coupon was removed and counted with the HPGe detector.

The 1-h soak times may not prove practical for many applications, so shorter times were investigated. In the next set of scoping tests, we exposed five materials to $0.1 \mathrm{M}$ and $0.5 \mathrm{M}$ ammonium chloride solutions. For each substrate, three contaminated coupons were placed in 10 $\mathrm{mL}$ of $0.1 \mathrm{M}$ ammonium chloride, and three coupons were placed in $10 \mathrm{~mL}$ of $0.5 \mathrm{M}$ ammonium chloride. Each coupon was exposed to the wash solution for three minutes, after which it was rinsed for 2-3 seconds with deionized water and left to dry overnight before counting. Solution aliquots were also removed from each Petri dish for $\gamma$-counting.

\subsection{Flow test}

For the flow testing, additional coupons (red brick, limestone, granite, concrete, and asphalt) were supplied by EPA (Table 2) as part of the material used in a broader testing program and used as received. These were previously soaked in deionized water, dried for 24 hours, and sealed on five sides with water-impermeable sealant [19]. We did note that the surface was free from obvious loose particulate or oils. The porosity was reported as $31 \%, 17 \%, 5 \%, 32 \%$, and $19 \%$ for brick, limestone, granite, concrete, and asphalt, respectively [20]. Note that the asphalt depicted in Fig. 1 has aggregates exposed to the test surface.

TABLE 2. Coupon material descriptions and sources.

\begin{tabular}{|c|l|l|l|l|}
\hline Material & \multicolumn{1}{|c|}{ Description } & Name & Locality & \multicolumn{1}{c|}{ Source } \\
\hline Red brick & Red, fine-grained & $\begin{array}{l}\text { Paving } \\
\text { brick }\end{array}$ & $\begin{array}{l}\text { Made } \\
\text { from red } \\
\text { Triassic } \\
\text { clay }\end{array}$ & $\begin{array}{l}\text { Triangle Brick } \\
\text { Company, } \\
\text { Durham, NC }\end{array}$ \\
\hline Limestone & $\begin{array}{l}\text { Light-grey, coarse-grained, } ~ 75 \\
\% \text { skeletal grains, remainder } \\
\text { calcite cement and trace }(1 \%) \\
\text { quartz, dolomite, pyrite, clay }\end{array}$ & Indiana & $\begin{array}{l}\text { South } \\
\text { central IN }\end{array}$ & $\begin{array}{l}\text { Cathedral Stone } \\
\text { Products, } \\
\text { Hanover Park, } \\
\text { MD }\end{array}$ \\
\hline
\end{tabular}




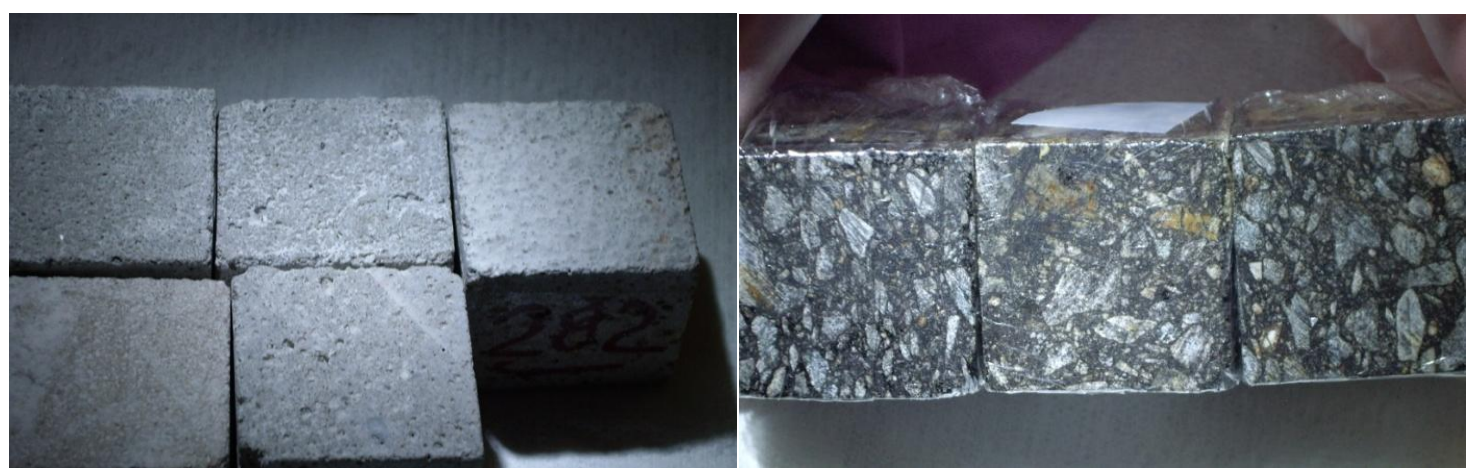

Figure 1. Typical coupons of concrete (left) and asphalt (right). The surface of the concrete reveals few aggregates while the asphalt surface is densely covered in aggregate material.

Coupons were contaminated with $100 \mu 1$ of dissolved cesium as described in Section 2.2. In some tests, coupons were contaminated with powdered ${ }^{137} \mathrm{CsCl}$. First, a flat piece of Teflon tape slightly larger than the coupon face was secured to a piece of soft filter paper. Then, $200 \mu \mathrm{L}$ of the dilute Cs-137 stock solution was pipetted drop by drop across the Teflon tape such that a pattern approximately the size of the coupon face was created. This was allowed to dry overnight. Then, the coupon was pressed firmly against the Teflon tape and rotated in a smearing motion in an effort to transfer the dried Cs-137 onto the coupon face. The resultant $\gamma$-activity was quantified in front of an HPGe detector. In the three trials with asphalt we produced 119, 70 and 79 counts per minute and in five trial for concrete we produced 1283, 1021, 584, 666, 341, and 611 counts per minute.

Each coupon was fit into an adjustable Teflon ${ }^{\circledR}$ holder (Fig. 2) clamped to a ring stand at an angle to allow maximum distribution of water. A small peristaltic pump was used to flow water over the coupon at a rate of $100 \mathrm{~mL} / \mathrm{min}$. The coupons were placed on top of a $5 \times 10 \mathrm{~cm}$ sheet of Parafilm ${ }^{\mathrm{TM}}$ to prevent the wash water from leaking across the backside of the Teflon ${ }^{\circledR}$ holder. 


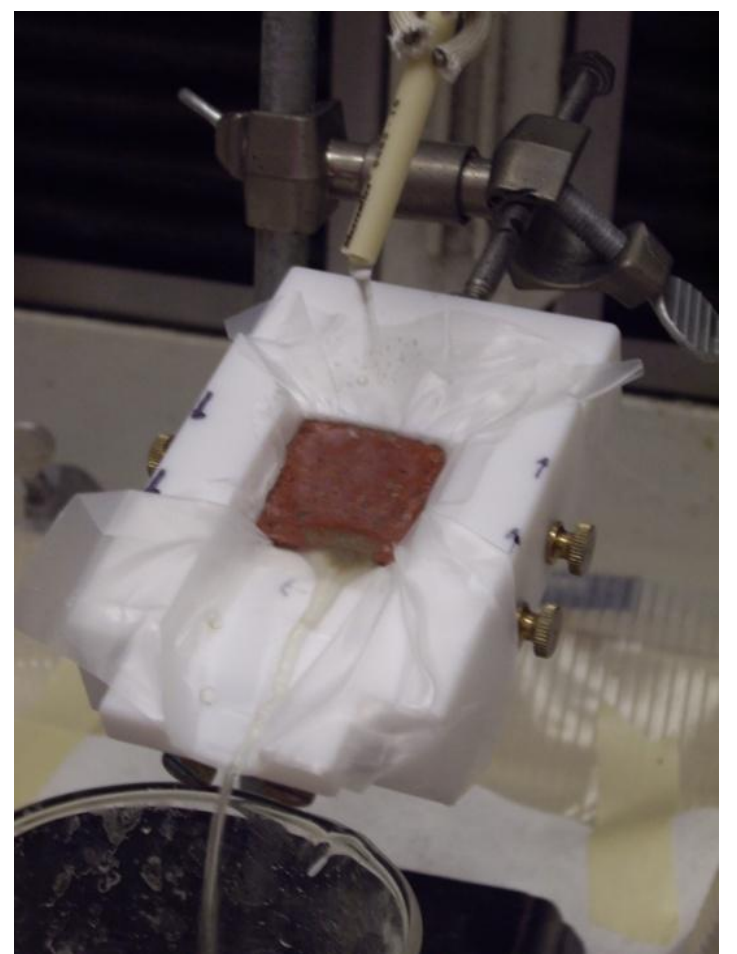

Figure 2. Schematic of flow system (left). A wash solution is pumped into the hood and flows over a brick coupon and into the collection beaker (right).

\subsection{RESULTS AND DISCUSSION}

\subsection{Concrete aggregate batch tests}

Ammonium chloride was shown to be an effective wash solution for removing cesium from concrete [12] and clay building materials $[11,12,21]$ due to its similar ion exchange properties [21]. More aggressive chemicals may be used to etch the surface and possibly improve the mobilization of cesium from the surfaces, but use of such chemicals may be prohibitive in a wide-area decontamination effort. Therefore, we were more interested in testing less hazardous chemicals.

We first examined the decontamination of concrete aggregate since these contain many types of sorption sites for cations and serves as a way to screen decontamination formulations for further testing. Indeed, Evans [22] summarized the literature of cesium sorption to cement (no aggregate) and pointed out NMR studies by Hanna et al. [23] that showed cesium remained in solution in Ordinary Portland Cement, suggesting water alone should leach the cesium from the cement phase. Our tests showed that cesium could be removed from the cement pieces with $0.1 \mathrm{M}$ $\mathrm{NH}_{4} \mathrm{Cl}$ up to $81 \%(\mathrm{n}=2)$, corroborating the findings of Hanna et al. [23]. Rudin et al. [24] measured the release of less than half to nearly $100 \%$ cesium into $0.01 \mathrm{M} \mathrm{CaCl}_{2}$ applied to various sulfate-resistant, crushed Portland cement samples with slow kinetics over 10 days. When aggregate was included, the $\mathrm{K}_{\mathrm{d}}$ for cesium increased. Jakubich et al. [25] showed that the partitioning coefficient $\left(\mathrm{K}_{\mathrm{d}}\right)$ for sorption increased on gneiss aggregate containing biotite and pyroxene and on iron oxides. Studies by Gusarov [20] and Maslova [26] showed the maximum 
$\mathrm{K}_{\mathrm{d}}$ for sorption of cesium into the same concrete coupons (crushed) used in the present study slowly approached a maximum of $2000 \mathrm{~mL} / \mathrm{g}$ over 24 hours, and cesium release into solutions containing $100 \mathrm{mM} \mathrm{Ca}^{2+}$ and $0.5 \mathrm{mM} \mathrm{K}^{+}$was also slow, suggesting that the aggregate plays a key role in retaining cesium onto the concrete. Therefore, we conclude from these studies that the kinetics for uptake and release of cesium is slow. Therefore, the individual values of the equilibrium $\mathrm{K}_{\mathrm{d}}$ may be of limited use in interpreting dynamic studies like ours. However, they still provide value to our study because individual $\mathrm{K}_{\mathrm{d}}$ values shed light on the phases that might be responsible for the lack of desorption of cesium from the surface and, thus, limits to its decontamination. Therefore, these past studies show that the aggregate phase is a meritable choice to screen the effect of decontamination solutions.

The coarse and fine aggregate, a river bed sediment in this particular mix, was examined by light microscopy and found to consist mostly of rounded quartz grains with minor (perhaps a few volume \%) feldspar and some dark minerals (probably pyroxene or hornblende). The mixture is dominated by quartz (transparent, translucent and pinkish grains), sandstone, and quartzite. Less abundant darker grains were amphibolite, granite, and mica-rich gneiss, as well as surfaces coated with weathered clay products and calcium carbonate.

We tested desorption of cesium as a function of ammonium chloride concentration for coarse aggregate (the results for fine aggregate are similar, data not shown) and observed an increase in cesium removal as the ammonium chloride concentration increased (Figure 3) with perhaps a plateau at $\geq 50 \mathrm{mM}$ salt. These results are expected based on DeWitt et al., where they found that desorption of cesium plateaued between $30 \mathrm{mM}$ and $200 \mathrm{mM} \mathrm{NH}_{4}{ }^{+}$. These results suggest that a wash system should employ very high concentrations of a competitive salt to maximize decontamination factors. These concentrations of salt are indeed worth noting, given that the concentration of total salt in sea water is about the same, $\sim 300 \mathrm{mM}$. However, the predominant salt in sea water is sodium, which has been proven ineffective for the decontamination of cesium [27] due to the high solvation energy of the sodium cation, which prevents inner sphere coordination. Thus, the bond strength between sodium and charged sites on clays and minerals is very weak and not competitive to cesium.

As this batch test format provided copious ions and solution volume, intimate mixing of the individual aggregate phases, and extended residence times, it is best used to help screen decontamination reagents for further testing. However, the surface of concrete will have varying degrees of available aggregate phases and include the problem of removing radionuclides from a porous surface where intimate mixing of the decontamination solution with the aggregate or cement phase will not be as optimal as described in the batch tests. To determine if this trend in cesium removal follows for more practical test formats that better mimic what may be necessary in a wide-area decontamination operation, we next measured the decontamination of monolithic coupons. 

ammonium chloride concentration (error bars display range of data based on duplicate samples).

\subsection{Static soak tests}

Asphalt, brick, limestone, granite, and concrete were initially investigated as being representative of porous urban construction materials present in critical infrastructure such as roadways, hospitals, public works, etc. The purpose of the static soak test was to determine the effect of salt concentration on coupon decontamination as a function of soak time given a copious supply of ammonium ions, water, and long residence times. In a practical sense, a long soak in solution may be achieved using a foam or gel-type decontamination formulation. The results (Fig. 4) show that $\geq 10 \mathrm{mM}$ salt produces the highest decontamination (\% Cs-137 removed), a slightly lower threshold than the results of the aggregate testing. In addition, at $10 \mathrm{mM}$ and $0.5 \mathrm{M}$, the decontamination continued to improve for soak times up to the $60 \mathrm{~min}$ limit we applied in these tests. Results of [11] suggest that $\mathrm{NH}_{4}{ }^{+}>0.2 \mathrm{M}$ only marginally improves cesium desorption, but there was a gap in the data between 0.03 and $0.2 \mathrm{M}$. The discrepancy at lower $\mathrm{NH}_{4}{ }^{+}$values between these tests on concrete coupons (i.e., fine and coarse aggregate in a cement matrix) may be a result of the role of cement. If some significant portion of the cesium remains in the cement phase (as solvated ions, based on Hanna et al.), then one would expect the decontamination to be less sensitive to the concentration of the $\mathrm{NH}_{4}{ }^{+}$ions. 


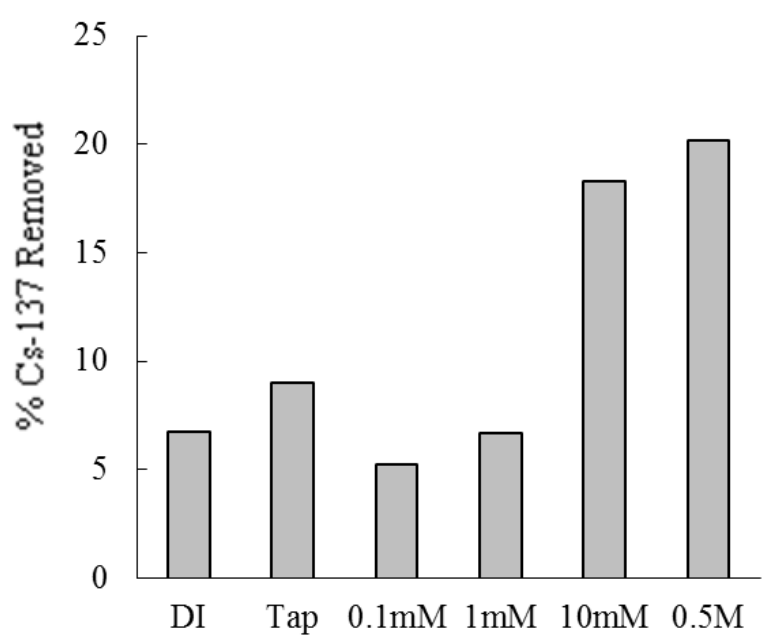

Figure 4. Activity of Cs-137 in solution (left) and \% removal from the surface of concrete coupons into various salt solutions (single coupon tests at each concentration).

However, 60 min soak times in a practical application may not be realistic since we would prefer to wash down building surfaces for a short period of time to cover a large area quickly. Therefore, we were interested in the decontamination after short residence times. We tested various building materials and focused on high ammonium salt, well above $10 \mathrm{mM}$ (Fig. 5) to eliminate the sensitivity of the results to $\mathrm{NH}_{4}{ }^{+}$concentration. Surprisingly, we found that there was a significant difference (t-test at $95 \%$ confidence level; $\mathrm{p}<0.003$ limestone; $\mathrm{p}<0.17$ brick; $\mathrm{p}<0.06$ granite; $p<0.25$ asphalt; $p<0.003$ concrete) between exposure for three minutes to ammonium solutions containing $0.1 \mathrm{M}$ and $0.5 \mathrm{M}$ salt that would not have been apparent from the data in Fig. 4. The trend was consistent between limestone, brick, granite, asphalt, and concrete samples. Removal of cesium from limestone increased from $5 \%$ to $22 \%$, brick from $6 \%$ to $18 \%$, granite from $24 \%$ to $55 \%$, asphalt from $25 \%$ to $46 \%$, and concrete from $8 \%$ to $28 \%$. 


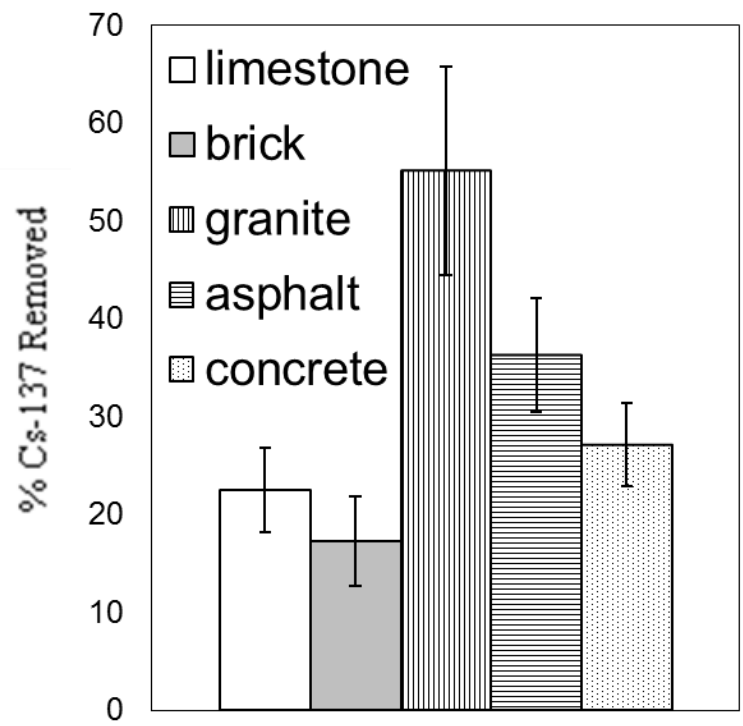

Figure 5. Desorption of cesium (percent removed) from the five substrates into $0.1 \mathrm{M}$ (left) and $0.5 \mathrm{M}$ (right) $\mathrm{NH}_{4} \mathrm{Cl}$ after a three-minute soak period (triplicate samples).

In absolute terms, the amount of cesium removed from the surface is sensitive to the material type. However, the results of Fig. 5 may also represent a worst-case scenario where cesium has been deposited onto the surface wet or allowed to age before a remediation response can be organized. Specifically, studies have shown that the deposition of wet cesium is significantly more difficult than fresh deposition in the dry state. For instance, Roed et al. [28] found that cesium associated with particles could be removed with a decontamination factor DF $=$ 3.0 while obtaining DF $=1.27$ for cesium that was condensed and solubilized into the sandstone surface. Sandalls [29] found that aerosolized cesium could be removed to $>85 \%$ from clay tile but only $40 \%$ could be removed when the cesium was deposited from a solution. Researchers at the U.S. EPA [30] deposited aerosolized $\mathrm{CsCl}$ in methanol onto concrete and were able to remove cesium with deionized water to a $\mathrm{DF}=2.2$. The explanation is simply that chemical ion exchange of solubilized cesium when dissolved in water compared to physically coating the surface with dry cesium salt. Accordingly, a decontamination activity ideally would be initiated shortly after the event to take advantage of better decontamination factors, and the logistical simplicity of utilizing $\mathrm{NH}_{4} \mathrm{Cl}$ salt may enable this.

\subsection{Flow tests}

While the static tests provided insight into the effect of salt concentration on the removal of cesium, the practical aspect of those tests might be less apparent since decontamination techniques utilizing concentrated salt solution may not be designed with a static dwell time of 60 min or even $3 \mathrm{~min}$, as we designed the tests in Section 3.2. The decontamination method may be a continuous flow of decontamination solution over the surface. Therefore, we designed a flow test apparatus to provide an incremental improvement in the test methodology for practical applications.

Therefore, to help study the potential advantage of rapid application of $\mathrm{NH}_{4} \mathrm{Cl}$ 

$(100 \mathrm{~mL} / \mathrm{min})$ to compare decontamination of cesium deposited in dry form and in soluble (or wet) form on concrete coupons (Fig. 6). The decontamination of dry-deposited cesium with tap water or $0.5 \mathrm{M} \mathrm{NH}_{4} \mathrm{Cl}$ was much improved over decontamination of wet-deposited cesium using $0.5 \mathrm{M}$ $\mathrm{NH}_{4} \mathrm{Cl}$. For dry deposition, we achieved 75-80\% decontamination with the $\mathrm{NH}_{4}{ }^{+}$and highly variable decontamination of 32-70 \% with tap water. Decontamination of cesium was little improved with successive steps, even in the dry deposition cases suggesting that upon wetting, the residual ionic cesium becomes -bound to the concrete or is physically trapped/transported within the pore network. This phenomenon may point to the need, in some cases, for higher flow rates to minimize the time cesium has to bind to the substrate before being captured, capping sorption sites with like cations $\left(\mathrm{NH}_{4}{ }^{+}, \mathrm{K}^{+}\right)$during decontamination, and/or finding a sorbent material that can be placed in the wash water to immediately sequester the mobile cesium and prevent re-adsorption.

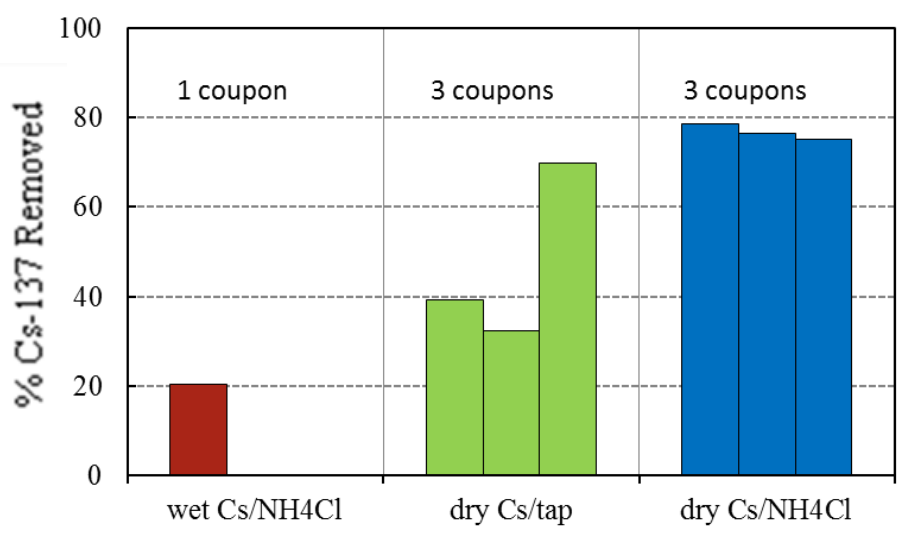

Cs contamination/wash solution $(100 \mathrm{~mL} / \mathrm{min})$

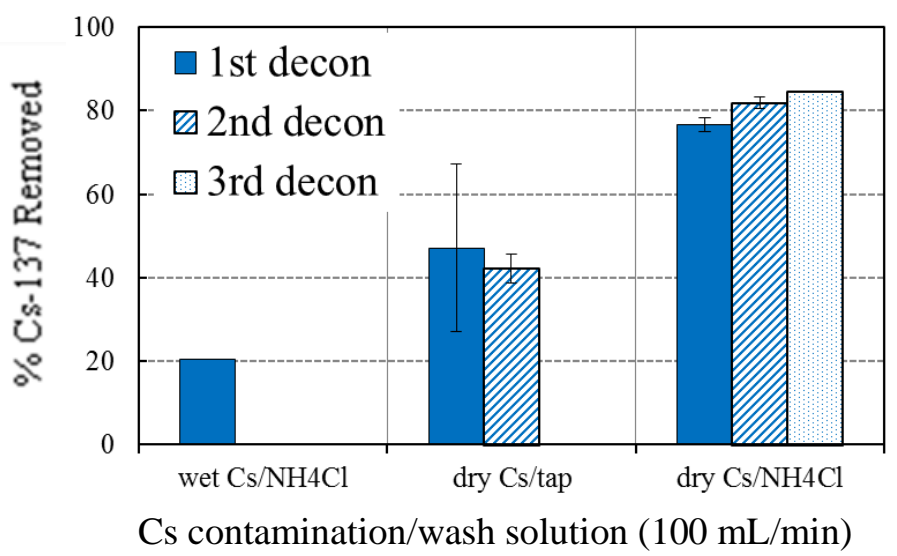

Figure 6. Single (top) and successive (bottom) decontaminations of cesium from concrete coupons for dry and wet deposition.

Tests identical to those reported above for concrete were completed on asphalt coupons after dry and wet deposition of cesium (Fig. 7). First, the inclusion of a wetting agent (the surfactant, sodium dodecyl sulfate) markedly improved decontamination. We suspect this 
improved decontamination was due to the improved coverage of the hydrophobic asphalt surface (visibly obvious) by the wash water during the flow tests as flow tests with tap water or salt alone produced isolated rivulets along the coupon surface. Comparing wet and dry contamination, we note that even tap water can be very effective against dry deposition. Successive decontamination experiments were also completed on the samples of asphalt that had been prepared by dry deposition of cesium. The decontamination improved slightly, from $93 \%$ to an average of $95 \%$ total removed, after two successive decontaminations.
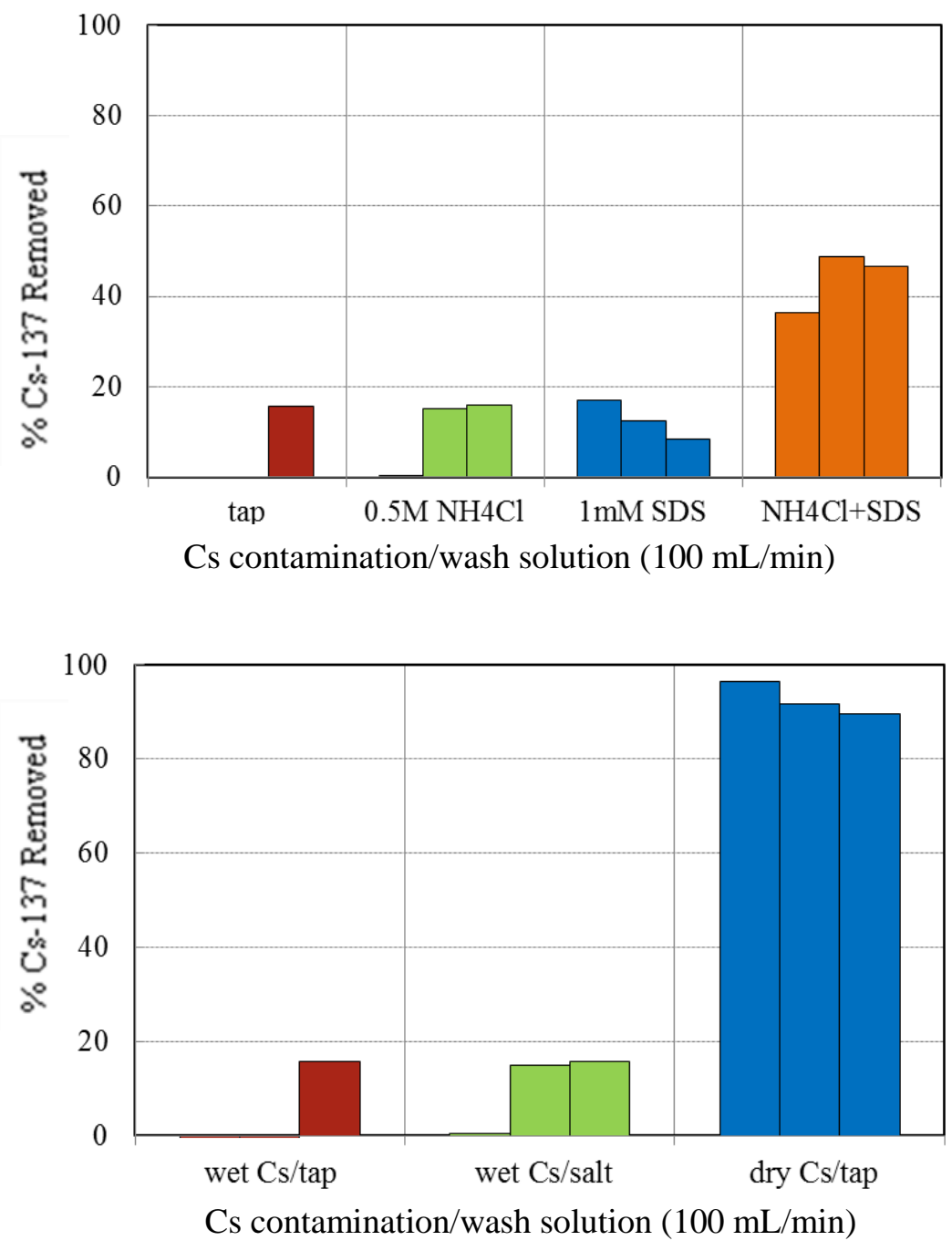

Figure 7. Decontamination of Cs-137 from asphalt coupons in flow tests following wet deposition of cesium (top) into several wash solutions and its removal for dry and wet deposition of cesium (bottom).

\subsection{CONCLUSIONS}


We have established the concentration of ammonium salt solutions needed to maximize removal of Cs-137 from a common concrete formulation by showing that improved decontamination factors can be obtained more consistently with $0.5 \mathrm{M} \mathrm{NH} \mathrm{N}_{4} \mathrm{Cl}$ than even with $0.1 \mathrm{M}$. The results are consistent between the concrete, asphalt, granite, brick, and limestone surfaces we tested although they differ slightly from the results [11] of our own aggregate phase tests. In addition, we saw a dramatic improvement in the decontamination of cesium that was deposited dry onto concrete and asphalt surfaces and encountered difficulty in removing cesium from such coupons once the residual dissolved. This observation supports previous studies and highlights the importance of being able to perform decontamination activities quickly before the deposited cesium has time to dissolve into the building material to maximize removal. In addition, these results help guide responders on best practices to maximize the decontamination effort. Our data suggests that increasing the salt concentration to as high as $0.5 \mathrm{M}$ would provide benefit and consistency in the decontamination effort for all building material surfaces. However, such high concentrations of salt would likely require additional planning in order to produce sufficient volumes of such salty water for wide area dissemination. In addition, one must consider how to handle the waste water containing low concentrations of radioactive cesium and high concentrations of salt. Although the international community has had some experience with handling seawater contaminated with cesium (most recently at the Fukushima Daiichi reactor site), the use of such chemically-similar salt such as ammonium ions will require special consideration.

\section{ACKNOWLEDGMENTS}

The authors thank M. Magnuson and J. Bursey for thoughtful comments and suggestions to improve the article. The U.S. Environmental Protection Agency through its Office of Research and Development partially funded and collaborated with the Technical Support Working Group/Combating Terrorism Technical Support Office in the research described here under Interagency Agreement 92380201. It has been subjected to the Agency's review and has been approved for publication. Note that approval does not signify that the contents necessarily reflect the views of the Agency. Mention of trade names, products, or services does not convey official EPA approval, endorsement, or recommendation. The submitted manuscript has been created by UChicago Argonne, LLC, Operator of Argonne National Laboratory (“Argonne”). Argonne, a U.S. Department of Energy Office of Science laboratory, is operated under Contract No. DE-AC02-06CH11357. The U.S. Government retains for itself, and others acting on its behalf, a paid-up nonexclusive, irrevocable worldwide license in said article to reproduce, prepare derivative works, distribute copies to the public, and perform publicly and display publicly, by or on behalf of the Government.

\subsection{REFERENCES}



WT-1488, Civil Effects Test Group, Nevada Test Site, (1966).

[2] T. McKenna, J. Trefethen, K. Gant, J. Jolicoeur, G. Kuzo, G. Athey, Response Technical Manual, in, US Nuclear Regulatory Commission, 1996, pp. 488.

[3] J.R. Simmonds, S.M. Haywood, G.S. Linsley, Accidental Release of Radionuclides: A Preliminary Study of the Consequences of Land Contamination, NRPD-R133, National Radiological Protection Board, United Kingdom, (1982).

[4] K. Heinz-Neeb, Decontamination in Nuclear Power Plants, in: The Radiochemistry of Nuclear Power Plants with Light Water Reactors, Walter de Gruyter, New York, 1997. [5] Decontamination Techniques Used in Decommissioning Activities, NEA Task Group on Decontamination, Nuclear Energy Agency-OECD, (2008).

[6] H.L. Gjorup, N.O. Jensen, P.H. Jensen, L. Kristensen, O.J. Nielsen, E.L. Petersen, T. Petersen, J. Roed, S. Thykier-Nielsen, F.H. Vinther, L. Warming, A. Aarkrog, Radioactive Contamination of Danish Terrirory after Core-melt Accidents at the Barseback Power Plant, Riso Report No. 462, Riso National Laboratory, (1982).

[7] L. Warming, Weathering and Decontamination of Radioactivity Deposited on Asphalt Surfaces, Riso-M-2273, Riso National Laboratory, (1982).

[8] L. Warming, Weathering and Decontamination of Radioactivity Deposited on Concrete Surfaces, Riso-M-2473, Riso National Laboratory, (1984).

[9] F.J. Sandalls, Removal of Radiocaesium from Urban Surfaces Contaminated as the Result of a Nuclear Accident, AERE R 12355, United Kingdom Atomic Energy Authority, (1987).

[10] B.G. Ahn, H.J. Won, W.Z. Oh, Decontamination of building surface using clay suspension, Journal of Nuclear Science and Technology, 32 (1995) 7.

[11] H. DeWitt, W. Goldammer, H. Brenk, R. Hille, H. Jacobs, K. Frenkler, Decontamination of urban areas after nuclear accident, in: Proceedings of an International Symposium on Recovery Operations in the Event of Nuclear Accident or Radiological Emergency, IAEA-SM-316/44, International Atomic Energy Agency, Vienna, 1989, pp. 355-363.

[12] J. Real, F. Persin, C. Camarasa-Claret, Mechanisms of desorption of 134Cs and 85Sr aerosols deposited on urban surfaces, Journal of Environmental Radioactivity, 62 (2002) 1-15.

[13] J. Drake, Radiological Decontamination Technologies for RDD Recovery, in:

Decontamination Research and Development Conference, US Environmental Protection Agency, Durham, NC, 2011, pp. 26.

[14] R.L. Demmer, Large-scale, Urban Decontamination: Developments, Historical Examples, and Lessons Learned, in: Waste Management'07, Tucson, AZ, 2007.

[15] R. Demmer, E. Snyder, J. Drake, R. James, Understanding Contamination, in: Waste Management Conference 2010, Phoenix, AZ, 2012.

[16] Decontamination of Cesium, Cobalt, Strontium, and Americium from Porous Surfaces, EPA/600/R-13/232, Technology Evaluation Report, U.S. Environmental Protection Agency, Washington, DC, (2013).

[17] M. Kaminski, C. Mertz, N. Kivenas, Irreversible wash aid additive for mitigation of urban, radioactive contaminations, Waste Management Conference 2014, Phoenix, AZ, (2014).

[18] Decontamination Effect of Decontamination Work, Ministry of the Environment Japan, (2013). 
[19] Water Wash Down of Radiological DispersalDevice (RDD) Material on Urban Surfaces: Effect of Washing Conditions onCs Removal Efficacy, EPA 600/R-12/068, Technology Evaluation Report, U.S. Environmental Protection Agency, Washington, DC, (2012). [20] A. Gusarov, N. Il'icheva, A. Konoplev, S.D. Lee, K. Maslova, V. Popov, I. Stepina, Fate and transport of radiocesium in urban building materials, Radioprotection, 46 (2011) S265-S269. [21] J. Sinnaeve, M. Olast, Improvement of Practical Countermeasures: The Urban Environment, Post-Chernobyl Action, EUR 12555 EN, Commission of the European Communities, Brussels, (1991).

[22] N.D.M. Evans, Binding mechanisms of radionuclides to cement, Cement and Concrete Research, 38 (2008) 543-553.

[23] J.V. Hanna, L.P. Aldridge, E.R. Vance, Cs speciation in cements, Mat. Res. Soc. Symp. Proc, 663 (2001) 89-101.

[24] M.J. Rudin, W.H. Johnson, S.M. Steinberg, Sorption/desorption of cesium in sulfate-resistant Portland cements, Journal of Radioanalytical and Nuclear Chemistry, 264 (2005) 501-504.

[25] A.T. Jakubick, R.W. Gillham, I. Kahl, M. Robin, Attenuation of Pu, Am, Cs, and Sr mobility in concrete, in: Mat. Res. Soc. Symp. Proc., 1987, pp. 355-368.

[26] K. Maslova, I. Stepina, A. Konoplev, V. Popov, A. Gusarov, F. Pankratov, S.D. Lee, N. Il'icheva, Fate and transport of radiocesium, radiostrontium and radiocobalt on urban building materials, Journal of Environmental Radioactivity, 125 (2013) 74-80.

[27] T. Missana, M. García-Gutiérrez, A. Benedicto, C. Ayora, K. De-Pourcq, Modelling of Cs sorption in natural mixed-clays and the effects of ion competition, Applied Geochemistry, 49 (2014) 95-102.

[28] J. Roed, K.G. Andersson, Clean-up of urban areas in the CIS countries contaminated by Chernobyl fallout, Journal of Environmental Radioactivity, 33 (1996) 10.

[29] F.J. Sandalls, Removal of radiocaesium from urban surfaces, Radiation Protection Dosimetry, 21 (1987) 4.

[30] Water Wash Down of Radiological Dispersal Device (RDD) Material on Urban Surfaces: Effect of Washing Conditions on Cs Removal Efficacy, EPA/600/R-12/068, U.S. Environmental Protection Agency, Washington, DC, (2012). 